\title{
Ten health stories that mattered this week: Feb. 16-20
}

- Health Canada is under pressure to reverse its decision to allow the sale of nosodes, homeopathic products sometimes promoted as alternatives to vaccines. Though Health Canada states nosodes should not be marketed this way, some natural health practitioners have promoted the products to prevent illnesses such as measles and whooping cough.

- Secret shoppers may soon be testing how willing retailers are to sell electronic cigarettes to young people. Health Canada issued a $\$ 350000$ tender for the project, which will see teenagers masquerade as shoppers at 4000 or more stores.

- Health Canada approved the new HPV vaccine Gardasil 9, which covers five HPV strains (types 31, 33, 45,52 and 58) in addition to the four strains $(6,11,16$ and 18$)$ covered by the vaccine used since 2006 . The new vaccine is expected to be available in the spring.

- British Columbia has been able to deliver a balanced budget for three years running largely because it has controlled spending on health care. Some of the strategies used include negotiating with drug companies to lower drug costs, getting better deals with medical laboratories and encouraging more collaboration among health authorities.

- There have been at least 17 cases of measles in Ontario. The latest case, in the Niagara Region, involves an unvaccinated woman.

- British Columba lost about $\$ 500000$ in federal health transfer payments over the past two years as a penalty for extra-billing charges at diagnostic clinics and hospitals (private and public). Since 1994, provinces have lost nearly $\$ 10$ million in federal funding for extra-billing, though Newfoundland and Labrador is the only other province to be penalized in the past three years.

- The union representing 3400 health professionals in Canada's public service has pulled out of collective bargaining with the Treasury Board. The union says the health professionals, many of whom are considered essential workers, should have access to arbitration rather than being forced to strike if contract negotiations fail.

- The Alberta government once again expressed its interest in bringing back health care premiums, which the province eliminated in 2009. The province is in financial straits because of a revenue shortfall caused by low oil prices.

- A third of employees in Ontario don't have employer-provided medical or dental benefits, according to a paper by the Wellesley Institute, a nonprofit research institute based in Toronto. Low-income earners and women are less likely to have benefits.

- A child in Saskatchewan who ate cookies laced with marijuana spent two days in intensive care after being admitted to hospital unconscious. The child's father, who made the cookies, has been charged with criminal negligence causing bodily harm. — Roger Collier, CMAJ

CMAJ 2015. DOI:10.1503/cmaj.109-5006 